Pacific Journal of Mathematics

FIXED POINT THEOREMS FOR POINT-TO-SET MAPPINGS

H. M. Ko 


\title{
FIXED POINT THEOREMS FOR POINT-TO-SET MAPPINGS AND THE SET OF FIXED POINTS
}

\author{
HWEI-MEI Ko
}

Let $X$ be a Banach space and $K$ be a nonempty convex weakly compact subset of $X$. Belluce and Kirk proved that (1) If $f: K \rightarrow K$ is continuous, inf $f_{x \in K}\|x-f(x)\|=0$ and $I-f$ is a convex mapping, then $f$ has a fixed point in $K$. (2) If $f: K \rightarrow K$ is nonexpansive and $I-f$ is a convex mapping on $K$, then $f$ has a fixed point in $K$. In this paper the concept of convex mapping has been extended to pointto-set mappings. Theorems 1 and 2 in $\S 2$ extend the above fixed point theorems by Belluce and Kirk.

Let $W$ stand for the set of fixed points of $f: K \rightarrow c c(K)$. The set $W$ is called a singleton in a generalized sense if there is $x_{0} \in W$ such that $W \subset f\left(x_{0}\right)$. In $\S 3$ two examples are given to show that $W$ is not necessarily a singleton in a generalized sense if $f$ is strictly nonexpansive or if $I-f$ is convex. But one can be sure that $W$ is a convex set if $I-f$ is a convex or a semiconvex mapping.

1. Preliminaries.

Notations AND DEFINITIONS. Let $X$ be a topological space, define

1. $2^{X}=$ the family of all nonempty closed subsets of $X$.

2. $b(X)=\left\{A \in 2^{X} ; A\right.$ is bounded $\}$, where $X$ is a metric space.

3. $k(X)=\left\{A \in 2^{X} ; A\right.$ is convex $\}$, where $X$ is a linear topological space.

4. $\operatorname{cpt}(X)=\left\{A \in 2^{X} ; A\right.$ is compact $\}$.

5. $c c(X)=k(X) \cap \operatorname{cpt}(X)$, where $X$ is a linear topological space.

In the remainder of this section we assume $X$ to be a metric space with metric $d$, unless otherwise stated.

6. Let $x \in X$ and $r>0$, define $S(x, r)=\{y \in X ; d(y, x)<r\}$.

7. For $x \in X, A \in 2^{X}$, define $d(x, A)=\inf \{d(x, y) ; y \in A\}$.

8. Given $A \in 2^{X}$ and $r>0$, define $V_{r}(A)=\{x \in X ; d(x, A)<r\}$.

Lemma 1. Let $x, y \in X$ and let $A$ be a nonempty subset of $X$. Then $d(x, A) \leqq d(x, y)+d(y, A)$.

This is a simple consequence of the triangle inequality.

DeFinition 1. Let $X$ be a topological space. A mapping 
$f: X \rightarrow 2^{x}$ is said to be upper semicontinuous (abbreviated by u.s.c.) at $x_{0}$ if for any open set $U$ containing $f\left(x_{0}\right)$, there exists a neighborhood $V$ of $x_{0}$ such that $f(y) \subset U$ for any $y \in V$. The mapping $f$ is said to be u.s.c. in $X$ if it is u.s.c. at any $x$ in $X$.

Definition 2. A map $f: X \rightarrow b(X)$ is continuous if it is continuous from the metric topolgy of $X$ to the Hausdorff metric topology of $b(X)$.

Definition 3. A mapping $f: X \rightarrow b(X)$ is nonexpansive on $X$ if $D(f(x), f(y)) \leqq d(x, y)$ for any $x, y$ in $X$, where $D$ is the Hausdorff metric on $b(X)$.

Definition 4. A mapping $f: X \rightarrow b(X)$ is a contraction mapping if there is $0 \leqq k<1$, such that $D(f(x), f(y)) \leqq k d(x, y)$ for any $x, y \in X$.

It is clear that a nonexpansive mapping $f: X \rightarrow b(X)$ is continuous. For the relation between a continuous map and an upper semicontinuous map, we have the following:

Proposition 1. If $f: X \rightarrow \operatorname{cpt}(X)$ is continuous, then it is upper semicontinuous.

REMARK 1. The condition that the values of $f$ are compact subsets is not removable in the above proposition. As a matter of fact a nonexpansive mapping $f$ on $X$ into $2^{X}$ may fail to be upper semicontinuous. Examples like the following seem to be in the folklore.

Example 1. Let $X=[0,1] \times[0,1]-\{(0,1)\}$ with the usual metric. Let $(x, y) \in X$, define

$$
f((x, y))=\left\{\begin{array}{l}
\text { the segment }\{(x, z) ; z \in[0,1]\} \text { if } x \neq 0 . \\
\text { the segment }\{(0, z) ; z \in[0,1)\} \text { if } x=0 .
\end{array}\right.
$$

Then $f: X \rightarrow 2^{x}$ is nonexpansive on $X$, but it is not u.s.c. at $(0, y)$ for any $y \in[0,1)$. Because if we take

$$
U=\{(x, y) \in X ; x+y<1\},
$$

then $U$ is open and contains $f((0, y))$. However $U$ does not contain $f((x, z))$ for $(x, z) \in X$ and $x \neq 0$. Therefore no neighborhood of $(0, y)$ exists such that $U$ contains the image of $f$ at every point of the neighborhood. That is, $f$ is not u.s.c. at $(0, y)$. 
Definition 5. A real valued function $g$ on $X$ is said to be lower semicontinuous on $X$ if for any real number $a$, the set

$$
\{x \in X ; g(x)>a\}
$$

is open in $X$.

Proposition 2. If $f: X \rightarrow 2^{X}$ is upper semicontinuous, then the function $g$, where $g(x)=d(x, f(x))$, is lower semicontinuous.

Proof. Let $a$ be a real number and $x_{0} \in A=\{x ; g(x)>a\}$. We want to prove that $A$ is an open set. Let $r=g\left(x_{0}\right)-a$, then $r>0$ and the open set $V_{r / 3}\left(f\left(x_{0}\right)\right)$ contains $f\left(x_{0}\right)$. By the upper semicontinuity of $f$, there exists a neighborhood $V$ of $x_{0}$ such that

$$
f(y) \subset V_{r / 3}\left(f\left(x_{0}\right)\right)
$$

for any $y \in V$. We may assume $V \subset S\left(x_{0}, r / 3\right)$. Let $U=V_{r / 3}\left(f\left(x_{0}\right)\right)$. Then $z \in U$ implies

$$
\begin{aligned}
d\left(x_{0}, z\right) & \geqq d\left(x_{0}, f\left(x_{0}\right)\right)-d\left(z, f\left(x_{0}\right)\right) \quad(\text { by Lemma } 1) \\
& >r+a-r / 3=a+2 r / 3 .
\end{aligned}
$$

Therefore

$$
d\left(x_{0}, U\right)=\inf \left\{d\left(x_{0}, z\right) ; z \in U\right\} \geqq a+2 r / 3 .
$$

Thus $y \in V$ implies

$$
\begin{aligned}
d(y, f(y)) & \geqq d(y, U) \geqq d\left(x_{0}, U\right)-d\left(x_{0}, y\right) \quad(\text { by Lemma } 1) \\
& \geqq a+2 r / 3-r / 3=a+r / 3>a .
\end{aligned}
$$

Hence $y \in V$ implies $y \in A$. Thus $A$ is open. Therefore $g$ is lower semicontinuous.

2. Fixed point theorems. First we state a well known fixed point theorem for a point-to-set contraction mapping (cf. [5] p. 479 for the proof): Let $K$ be a nonempty bounded closed subset of a complete metric space $(X, d)$. If $f: K \rightarrow b(K)$ is a contraction mapping, then $f$ has a fixed point in $K$.

The space $X$ in the sequel is assumed to be a Banach space unless otherwise stated.

Definition 6. A mapping $f$ from $X$ into $2^{\mathrm{r}}$ is said to be convex if for any $x, y \in X$ and $m=\lambda x+(1-\lambda) y$ with $0 \leqq \lambda \leqq 1$, and any $x_{1} \in f(x), y_{1} \in f(y)$, there exists $m_{1} \in f(m)$ such that

$$
\left\|m_{1}\right\| \leqq \lambda\left\|x_{1}\right\|+(1-\lambda)\left\|y_{1}\right\| \text {. }
$$


Definition 7. A mapping $f: X \rightarrow 2^{X}$ is called semiconvex on $X$ if for any $x, y \in X, m=\lambda x+(1-\lambda) y$, where $0 \leqq \lambda \leqq 1$, and any $x_{1} \in f(x), y_{1} \in f(y)$, there exists $m_{1} \in f(m)$ such that

$$
\left\|m_{1}\right\| \leqq \max \left\{\left\|x_{1}\right\|,\left\|y_{1}\right\|\right\} \text {. }
$$

REMARK 2. A convex mapping is semiconvex, but the converse is not true. Take the mapping $f(x)=\sqrt{x}, x \in[0,1]$, for instance. The map $f$ is semiconvex because it is strictly increasing. But $f$ is not convex, for example take $x=1$ and $y=0$,

$$
m=1 / 4=1 / 4 \cdot 1+3 / 4 \cdot 0,
$$

then $f(1)=1, f(0)=0$, but

$$
f(m)=\sqrt{1 / 4}=1 / 2 \not \subset 1 / 4 f(1)+3 / 4 f(0)=1 / 4 .
$$

Lemma 2. Let $f: X \rightarrow 2^{X}$, and let $I: X \rightarrow X$ be the identity mapping. If $I-f$, where $(I-f)(x)=\{x-y ; y \in f(x)\}$, is convex (semiconvex), then for any $x, y \in X$ and $m=\lambda x+(1-\lambda) y, 0 \leqq \lambda \leqq 1$, we have

$$
\begin{aligned}
d(m, f(m)) & \leqq \lambda d(x, f(x))+(1-\lambda) d(y, f(y)) \\
(d(m, f(m)) & \leqq \max \{d(x, f(x)), d(y, f(y))\})
\end{aligned}
$$

Proof. Let $x_{n} \in f(x)$ be such that $\left\|x_{n}-x\right\| \rightarrow d(x, f(x))$ and $y_{n} \in f(y)$ be such that $\left\|y_{n}-y\right\| \rightarrow d(y, f(y))$. Let $I-f$ be a convex mapping, then there exists $m_{n} \in f(m)$ such that

$$
\left\|m-m_{n}\right\| \leqq \lambda\left\|x-x_{n}\right\|+(1-\lambda)\left\|y-y_{n}\right\| \text {. }
$$

Now

$$
d(m, f(m)) \leqq \inf _{n \geqq 1}\left\|m-m_{n}\right\| \leqq \lambda\left\|x-x_{n}\right\|+(1-\lambda)\left\|y-y_{n}\right\|
$$

for any $n \geqq 1$. Thus

$$
\begin{aligned}
d(m, f(m)) & \leqq \lambda\left\|x-x_{n}\right\|+(1-\lambda)\left\|y-y_{n}\right\| \\
& \longrightarrow \lambda d(x, f(x))+(1-\lambda) d(y, f(y)) .
\end{aligned}
$$

Similarly one can prove that

$$
d(m, f(m)) \leqq \max \{d(x, f(x)), d(y, f(y))\},
$$

if $I-f$ is semiconvex.

Lemma 3. Let $f: X \rightarrow \operatorname{cpt}(X)$ be a mapping such that for any $x, y \in X$ and any $m=\lambda x+(1-\lambda) y, 0 \leqq \lambda \leqq 1$, we have 


$$
\begin{aligned}
d(m, f(m)) & \leqq \lambda d(x, f(x))+(1-\lambda) d(y, f(y)) \\
(d(m, f(m)) & \leqq \max \{d(x, f(x)), d(y, f(y))\} \text { respectively })
\end{aligned}
$$

Then $I-f$ is a convex mapping (semiconvex mapping respectively).

Proof. Let $x_{1} \in f(x), y_{1} \in f(y)$; we have

$$
d(x, f(x)) \leqq\left\|x-x_{1}\right\| \text { and } d(y, f(y)) \leqq\left\|y-y_{1}\right\| \cdot
$$

Since $f(m)$ is compact, there is an $m_{1} \in f(m)$ such that

$$
\left\|m-m_{1}\right\|=d(m, f(m)) \leqq \lambda d(x, f(x))+(1-\lambda) d(y, f(y)) .
$$

Therefore $\left\|m-m_{1}\right\| \leqq \lambda\left\|x-x_{1}\right\|+(1-\lambda)\left\|y-y_{1}\right\|$. Hence $I-f$ is a convex mapping. Similarly one can prove, under the condition that $d(m, f(m)) \leqq \max \{d(x, f(x)), d(y, f(y))\}$, that $I-f$ is a semiconvex mapping.

Lemmas 2 and 3 characterize the convexity (semiconvexity) of $I-f$ in terms of the distance between a point and its image under $f$, where $f$ is a mapping from $X$ into $\operatorname{cpt}(X)$. The following lemma is a simple consequence of Lemma 2 .

Lemma 4. Let $f: X \rightarrow 2^{X}$, define

$$
H_{r}=\{x \in X: d(x, f(x)) \leqq r\},
$$

where $r \geqq 0$. If $I-f$ is a semiconvex mapping on $X$, then $H_{r}$ is convex.

THEOREM 1. Let $K$ be a nonempty weakly compact closed conver subset of $X$. If $f: K \rightarrow 2^{K}$ is upper semicontinuous and

$$
\inf \{d(x, f(x)) ; x \in K\}=0,
$$

and $I-f$ is a semiconvex mapping on $K$, then $f$ has a fixed point in $K$.

Proof. Let $r>0$, define $H_{r}$ as in Lemma 4. We see that $H_{r} \rightleftharpoons \varnothing$ for any $r>0$, since $\inf \{d(x, f(x)) ; x \in K\}=0$. As $f$ is upper semicontinuous, $H_{r}$ is closed (by Proposition 2). The map $I-f$ is semiconvex, hence $H_{r}$ is convex (by Lemma 4). The set $H_{r}$, being closed and convex, is weakly closed for each $r>0$. The family $\left\{H_{r} ; r>0\right\}$ has the finite intersection property. Therefore, by the weak compactness of $K$, we have $\bigcap_{r>0} H_{r} \neq \varnothing$. It is clear that any point in $\bigcap_{r>0} H_{r}$ is a fixed point of $f$. 
REMARK 3. A convex mapping is semiconvex, therefore Theorem 1 extends Theorem 4.1 of Belluce and Kirk [1]. Example 4.1 and 4.2 in [1], though they are point-to-point mappings, serve the purposes of demonstrating that "inf $\{d(x, f(x)) ; x \in K\}=0$ " or " $K$ is weakly compact" in Theorem 1 is indispensable. The following example, which is a special case of the example given by Kirk [4], shows that the semiconvexity of $I-f$ in Theorem 1 can not be removed.

ExAmple 2. Let $K=\left\{x \in l_{2} ;\|x\| \leqq 1\right\}$ be the closed unit sphere of the Hilbert space $l_{2}$. Then $K$ is closed, convex and weakly compact. Define $f$ on $K$ as follows: Let $x=\left(x_{1}, x_{2}, \cdots\right) \in K$, and let

$$
f(x)=\left(1-\|x\|, x_{1}, x_{2}, \cdots\right) \text {. }
$$

Then $\|f(x)\| \leqq 1$ and $\|f(x)-f(y)\| \leqq \sqrt{2}\|x-y\|$. i. e., $f$ is a continuous mapping on $K$ into $K$. We claim that

$$
\inf \{\|x-f(x)\| ; x \in K\}=0 .
$$

Let $x^{(n)}=\left(x_{1}, x_{2}, \cdots\right) \in l_{2}$ be such that $x_{1}=x_{2}=\cdots=x_{n^{2}}=1 / n$ and $x_{i}=0$ for $i>n^{2}$. Then $\left\|x^{(n)}\right\|=1$ and

We see that

$$
f\left(x^{(n)}\right)=\left(0, x_{1}, x_{2}, \cdots, x_{n^{2}}, 0, \cdots\right) .
$$

$$
\left\|x^{(n)}-f\left(x^{(n)}\right)\right\|=\sqrt{2} / n \rightarrow 0, \text { as } n \longrightarrow \infty .
$$

Hence $\inf \{\|x-f(x)\| ; x \in K\}=0$. But $I-f$ is neither convex nor semiconvex. For instance, let $x=(1 / 2,1 / 2,0, \cdots), y=(-1 / 2,-1 / 2$, $0, \cdots)$. Then $f(x)=(1-\sqrt{2} / 2,1 / 2,1 / 2,0, \cdots), f(y)=(1-\sqrt{2} / 2$, $-1 / 2,-1 / 2,0, \cdots),\|x-f(x)\|=(\sqrt{4-2 \sqrt{2}}) / 2<1,\|y-f(y)\|=$ $(\sqrt{12-6 \sqrt{2}} / 2<1$. Take $m=1 / 2(x+y)$, then $m=(0,0, \cdots)$ and $f(m)=(1,0, \cdots)$. Thus

$$
\|m-f(m)\|=1>\max \{\|x-f\{x)\|,\|y-f(y)\|\} \text {. }
$$

Therefore $I-f$ is not semiconvex and hence it is not convex. The map $f$ has no fixed point, for if $f(x)=x$, where $x=\left(x_{1}, x_{2}, \cdots\right) \in K$, then $x_{1}=x_{2}=\cdots$, and $\sum_{i=1}^{\infty} x_{i}^{2}<\infty$. Thus $x_{i}=0$ for $i \geqq 1$. But then $f(x)=(1,0, \cdots) \neq(0,0, \cdots)$.

Definition 8. A map $f: X \rightarrow 2^{x}$ is said to be asymptotically regular at $x_{0}$ if there exists a sequence of points such that $x_{n} \in f\left(x_{n-1}\right)$ and $\left\|x_{n}-x_{n-1}\right\| \rightarrow 0$ as $n \rightarrow \infty$.

Definition 8 is an extension of the definition of asymtotically 
regular point-to-point mapping given by Browder and Petryshyn [2]. One immediate result of Theorem 1 is the following corollary which extends the first part of Theorem 4.3 by Belluce and Kirk [1].

COROLlary 1. If $f: K \rightarrow 2^{K}$ is asymptotically rgular at some point in $K$, where $K$ is a nonempty closed convex weakly compact subset of $X$, and if $f$ is upper semicontinuous in $K$ such that $I-f$ is semiconvex, then $f$ has a fixed point in $K$.

Proof. Assume $f$ is asymptotically regular at $x_{0} \in K$; then there exists $x_{n} \in K$ such that $x_{n} \in f\left(x_{n-1}\right), n \geqq 1$, and $\left\|x_{n}-x_{n-1}\right\| \rightarrow 0$. Since $d\left(x_{n}, f\left(x_{n}\right)\right) \leqq\left\|x_{n+1}-x_{n}\right\| \rightarrow 0$, we have $\inf \{d(x, f(x)) ; x \in K\}=$ 0 ; hence Corollary 1 follows Theorem 1 .

THEOREM 2. Let $K$ be a nonempty weakly compact convex subset of $X$. If $f: K \rightarrow c c(K)$ is nonexpansive and if $I-f$ is semiconvex on $K$, then $f$ has a fixed point in $K$.

Proof. The map $f$ is nonexpansive, so it is upper semi-continuous (by Proposition 1). Theorem 2 follows Theorem 1 provided that the condition "inf $\{d(x, f(x)) ; x \in K\}=0$ " is satisfied. To prove this condition we have the following lemma.

Lemma 5. Let $K$ be a nonempty bounded closed convex subset of $X$. If $f: K \rightarrow b(K)$ is nonexpansive, then inf $\{d(x, f(x)) ; x \in K\}=0$.

Proof. Let $x_{0} \in K$. Denote $K_{0}=\left\{x-x_{0} ; x \in K\right\}$, then $K_{0}$ is a bounded closed convex subset of $X$ and $K_{0}$ contains 0 . Let $0 \leqq k<1$, define $f_{k}$ on $K_{0}$ as follows:

$$
f_{k}\left(x-x_{0}\right)=k\left(f(x)-x_{0}\right) .
$$

Then $f_{k}\left(x-x_{0}\right) \subset K_{0}$ for any $x-x_{0} \in K_{0}$, since $K_{0}$ is convex and contains zero element. As $f$ is nonexpansive, $f_{k}$ is contraction. By the fixed point theorem for point-to-set contraction mapping, there exists $x_{k} \in K$ such that

$$
x_{k}-x_{0} \in f_{k}\left(x_{k}-x_{0}\right)=k\left(f\left(x_{k}\right)-x_{0}\right) .
$$

Thus there is $y_{k} \in f\left(x_{k}\right)$ such that $x_{k}-x_{0}=k\left(y_{k}-x_{0}\right)$. Now

$$
\begin{aligned}
d\left(x_{k}, f\left(x_{k}\right)\right) & =\inf \left\{\left\|x_{k}-y\right\| ; y \in f\left(x_{k}\right)\right\} \leqq\left\|x_{k}-y_{k}\right\| \| \\
& =\left\|x_{0}+k\left(y_{k}-x\right)-y_{k}\right\|=(1-k)\left\|y_{k}-x_{0}\right\| .
\end{aligned}
$$

Therefore 


$$
\begin{aligned}
0 & \leqq \inf _{x \in K} d(x, f(x)) \leqq \inf _{0 \leqq k<1} d\left(x_{k}, f\left(x_{k}\right)\right) \\
& \leqq \inf _{0 \leqq k<1}(1-k)\left\|x_{0}-y_{k}\right\|=0,
\end{aligned}
$$

since the set $\left\{\left\|x_{0}-y_{k}\right\| ; 0 \leqq k<1\right\}$ is bounded. Hence

$$
\inf \{d(x, f(x)) ; x \in K\}=0 \text {. }
$$

3. The set of fixed points of a point-to-set mapping. Let $K$ be a closed convex subset of a Banach space $X$. Denote by $W$ the set of fixed points of a mapping $f: K \rightarrow 2^{K}$. Throught this section we assume $W$ to be nonempty.

Definition 9. A mapping $f: X \rightarrow b(X)$ is strictly nonexpansive if $D(f(x), f(y))<\|x-y\|$ for any $x, y \in X$ and $x \neq y$.

If $f$ is a point-to-point mapping, then the following properties are true.

(A) If $f$ is strictly nonexpansive, then $W$ is a singleton.

(B) If $f$ is nonexpansive and the norm of the Banach space is strictly convex, then $W$ is convex.

Statement (A) is no longer true for point-to-set mapping. For example, let $K$ be a set containing more than two points, then the set of fixed points of the mapping $f: K \rightarrow 2^{K}$, such that $f(x)=K$ for any $x \in K$, is $K$ itself which is not a singleton.

Statement (B) is obviously not true for a point-to-set mapping. However, as the next example shows, statement (B) is also not true for point-to-set mappings such that the image of each point is a nonempty compact convex set; note that the domain $K$ in our example is also convex.

Example 3. Let $K=[0,1] \times[0,1]$ with the usual norm. Define $f: K \rightarrow c c(K)$ by

$$
\begin{aligned}
f\left(\left(x_{1}, x_{2}\right)\right)= & \text { the triangle with vertices } \\
& (0,0),\left(x_{1}, 0\right) \text { and }\left(0, x_{2}\right) .
\end{aligned}
$$

Note that $f\left(\left(x_{1}, x_{2}\right)\right)$ is a degenerate triangle if $x_{1} x_{2}=0$. We see that $f$ is nonexpansive and the norm in $R^{2}$ is strictly convex. But the set $W$ of fixed points of $f$ is

$$
W=\left\{\left(x_{1}, x_{2}\right) ;\left(x_{1}, x_{2}\right) \in K \text { and } x_{1} x_{2}=0\right\}
$$

which is not convex. 
For a point-to-set mapping $f$, we have several choices for values of $f$, e.g., $f(x) \in k(X), f(x) \in \operatorname{cpt}(X)$ or $f(x) \in c c(X)$; among them, $f(x) \in c c(X)$ is the strongest assumption. For example, let $K$ be a compact convex subset of $X$, and let $g: X \rightarrow \operatorname{cpt}(X)$ be an upper semicontinuous mapping such that $g(x) \subset K$ for any $x \in K$, then $g$ does not always have a fixed point (e.g., the map $G$ of Strother [6], p. 990). But if we simply change $g$ as a mapping into $c c(X)$ instead of into $\operatorname{cpt}(X)$, then $g$ has a fixed point (see K. Fan [3]). In Example 3, although we have imposed the strongest condition on the values of $f$, i.e., $f(x) \in c c(K)$, that condition does not force $f$ to satisfy statement $(B)$. However the following proposition shows us a sufficient condition for $W$ to be convex.

Proposition 3. Let $f: K \rightarrow 2^{K}$ be a mapping such that $I-f$ is a semiconvex mapping on $K$. Then $W$ is convex.

Proof. If $I-f$ is semiconvex on $K$, then Lemma 4 shows that the set $H_{r}=\{x \in K ; d(x, f(x)) \leqq r\}$ is convex. Hence $W=H_{0}$ is convex.

Statement (A) can be rephrased as follows:

$\left(\mathrm{A}^{\prime}\right)$ If $f$ is strictly nonexpansive, then there is $x_{0}$ in $W$ such that $W \subset f\left(x_{0}\right)$.

For a point-to-point mapping $f$, statement $\left(A^{\prime}\right)$ implicitly shows $W$ to be a singleton. As for a point-to-set mapping $f$, statement $\left(A^{\prime}\right)$ does not require $W$ to be a singleton, and on the other hand it does not rule out the possibility that $W$ is a singleton. Therefore, it is reasonable to define $W$ to be a singleton in a generalized sense if there exists $x_{0} \in W$ such that $W \subset f\left(x_{0}\right)$. Unfortunately even for a strictly nonexpansive mapping $f$ on $K$ into $c c(K)$, the set $W$ of fixed points of $f$ is not necessarily a singleton in a generalized sense.

Example 4. Let $K=[0,1] \times[0,1]$, a subset of $R^{2}$ with the usual metric. Define $f ; K \rightarrow c c(K)$ as follows:

$$
\begin{aligned}
f\left(\left(x_{1}, x_{2}\right)\right)= & \text { the triangle with vertices } \\
& \left(x_{1} / 2,0\right),\left(x_{1} / 2,1\right) \text { and }(1,0) .
\end{aligned}
$$

Let $x=\left(x_{1}, x_{2}\right), y=\left(y_{1}, y_{2}\right) \in K$, with $x \neq y$, then

$$
D(f(x), f(y))=1 / 2\left|x_{1}-y_{1}\right|<d(x, y) .
$$

Hence $f$ is strictly nonexpansive. The set $W$ of fixed points of $f$ is 
the set bounded by positive $x, y$ axes and a branch of hyperbola $2 x+2 y-x y-2=0$. i.e.,

$$
W=\{(x, y) \in K ; 2 x+2 y-x y-2 \leqq 0\} .
$$

By an inspection of the shape of the set $W$, one sees that $W \varangle f((x, y))$ for any $(x, y) \in K$. Hence $W$ is not a singleton in a generalized sense.

The question arises: Is $W$ a singleton in a generalized sense if $f$ is nonexpansive and $I-f$ is convex? The answer is no. Let us consider the following example.

Example 5. Let $K=[0,1] \times[0,1]$ with the usual metric. Let $(x, y) \in K$, define

$$
f((x, y))=\text { the segment }\{(t, y) ; 0 \leqq t \leqq x / 2\} \text {. }
$$

Then $f: K \rightarrow c c(K)$ is nonexpansive. $I-f$ is a convex mapping. To show it, let $P=\left(x_{1}, y_{1}\right), Q=\left(x_{2}, y_{2}\right)$ both in $K$, and let

$$
M=\lambda P+(1-\lambda) Q,
$$

for some $0 \leqq \lambda \leqq 1$. Then

$$
\begin{aligned}
d(P, f(P)) & =x_{1} / 2, \\
d(Q, f(Q)) & =x_{2} / 2, \\
d(M, f(M)) & =1 / 2\left(\lambda x_{1}+(1-\lambda) x_{2}\right) \\
& =\lambda d(P, f(P))+(1-\lambda) d(Q, f(Q)) .
\end{aligned}
$$

By Lemma 3, we see that $I-f$ is convex on $K$. Now the set of fixed points of $f$ is $W=\{(0, y) ; 0 \leqq y \leqq 1\}$. But $W \leftarrow f((x, y))$ for any $(x, y) \in K$. Hence $W$ is not a singleton in the generalized sense.

The author would like to express her sincere thanks to Professor L. P. Belluce for his suggestions and Professor S. B. Nadler, Jr. for his constructive comments. This paper is based on the author's doctoral dissertation written under the guidance of Professor L. P. Belluce. The research was supported by National Research Council of Canada and by the University of British Columbia.

\section{REFERENCES}

1. L. P. Belluce and W. A. Kirk, Some fixed point theorems in metric and Banach spaces, Canad. Math. Bull., 12 (1969), 481-491.

2. F. E. Browder and W. V. Petryshyn, The solution by iteration of nonlinear functional equations in Banach spaces, Bull. Amer. Math. Soc., 72 (1966), 571-575. 
3. K. Fan, Fixed points and minimax theorem in locally convex topological spaces, Nat. Acad. of Sci. Proc., 38 (1952), 121-126.

4. W. A. Kirk, A fixed point theorem for mappings which do not increase distances, Amer. Math. Monthly, 72 (1965), 1004-1006.

5. S. B. Nadler, Jr, Multivalued contractive mappings, Pacific J. Math. 30 (1969), 475-488.

6. W. L. Strother, On an open question concerning fixed points Proc. Amer. Math. Soc., 4 (1953), 988-993.

Received April 12, 1971 and in revised form September 15, 1971.

UNIVERSITy OF BRITISH COLUMBIA

AND

National Tsing Hua University

Taiwan, Republic of China 



\section{PACIFIC JOURNAL OF MATHEMATICS}

\section{EDITORS}

\author{
H. SAMELSON \\ Stanford University \\ Stanford, California 94305 \\ C. R. HOBBY \\ University of Washington \\ Seattle, Washington 98105
}

\section{J. DuGundJI}

Department of Mathematics University of Southern California Los Angeles, California 90007

RICHARD ARENS

University of California

Los Angeles, California 90024

\section{ASSOCIATE EDITORS}
E. F. BECKENBACH
B. H. NeumanN
F. WOLF
K. YOSHIDA

\section{SUPPORTING INSTITUTIONS}

\author{
UNIVERSITY OF BRITISH COLUMBIA \\ CALIFORNIA INSTITUTE OF TECHNOLOGY \\ UNIVERSITY OF CALIFORNIA \\ MONTANA STATE UNIVERSITY \\ UNIVERSITY OF NEVADA \\ NEW MEXICO STATE UNIVERSITY \\ OREGON STATE UNIVERSITY \\ UNIVERSITY OF OREGON \\ OSAKA UNIVERSITY
}

\author{
UNIVERSITY OF SOUTHERN CALIFORNIA \\ STANFORD UNIVERSITY \\ UNIVERSITY OF TOKYO \\ UNIVERSITY OF UTAH \\ WASHINGTON STATE UNIVERSITY \\ UNIVERSITY OF WASHINGTON \\ AMERICAN MATHEMATICAL SOCIETY \\ NAVAL WEAPONS CENTER
}

The Supporting Institutions listed above contribute to the cost of publication of this Journal, but they are not owners or publishers and have no responsibility for its content or policies.

Mathematical papers intended for publication in the Pacific Journal of Mathematics should be in typed form or offset-reproduced, (not dittoed), double spaced with large margins. Underline Greek letters in red, German in green, and script in blue. The first paragraph or two must be capable of being used separately as a synopsis of the entire paper. The editorial "we" must not be used in the synopsis, and items of the bibliography should not be cited there unless absolutely necessary, in which case they must be identified by author and Journal, rather than by item number. Manuscripts, in duplicate if possible, may be sent to any one of the four editors. Please classify according to the scheme of Math. Rev. Index to Vol. 39. All other communications to the editors should be addressed to the managing editor, Richard Arens, University of California, Los Angeles, California, 90024.

50 reprints are provided free for each article; additional copies may be obtained at cost in multiples of 50 .

The Pacific Journal of Mathematics is published monthly. Effective with Volume 16 the price per volume (3 numbers) is $\$ 8.00$; single issues, $\$ 3.00$. Special price for current issues to individual faculty members of supporting institutions and to individual members of the American Mathematical Society: $\$ 4.00$ per volume; single issues $\$ 1.50$. Back numbers are available.

Subscriptions, orders for back numbers, and changes of address should be sent to Pacific Journal of Mathematics, 103 Highland Boulevard, Berkeley, California, 94708.

PUBLISHED BY PACIFIC JOURNAL OF MATHEMATICS, A NON-PROFIT CORPORATION

Printed at Kokusai Bunken Insatsusha (International Academic Printing Co., Ltd.), 270, 3-chome Totsuka-cho, Shinjuku-ku, Tokyo 160, Japan. 


\section{Pacific Journal of Mathematics}

\section{Vol. 42, No. $2 \quad$ February, 1972}

Stephen Richard Bernfeld, The extendability of solutions of perturbed scalar differential equations ................................. 277

James Edwin Brink, Inequalities involving $f_{-} p$ and $f^{(n)}{ }_{q}$ for $f$ with $n$

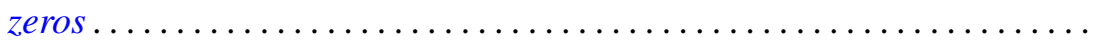

Orrin Frink and Robert S. Smith, On the distributivity of the lattice of filters of a groupoid

Donald Goldsmith, On the density of certain cohesive basic sequences .... 323

Charles Lemuel Hagopian, Planar images of decomposable continua . . . . . 329

W. N. Hudson, A decomposition theorem for biadditive processes ........ 333

W. N. Hudson, Continuity of sample functions of biadditive processes......

Masako Izumi and Shin-ichi Izumi, Integrability of trigonometric series.

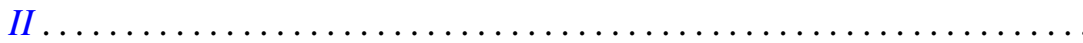

H. M. Ko, Fixed point theorems for point-to-set mappings and the set of

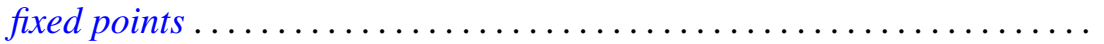

Gregers Louis Krabbe, An algebra of generalized functions on an open interval: two-sided operational calculus ...

Thomas Latimer Kriete, III, Complete non-selfadjointness of almost selfadjoint operators.................................

Shiva Narain Lal and Siya Ram, On the absolute Hausdorff summability of a Fourier series .

Ronald Leslie Lipsman, Representation theory of almost connected groups...

James R. McLaughlin, Integrated orthonormal series.... . .

H. Minc, On permanents of circulants.

Akihiro Okuyama, On a generalization of $\Sigma$-spaces.....

Norberto Salinas, Invariant subspaces and operators of class $(S)$

James D. Stafney, The spectrum of certain lower triangular matrices as operators on the $l_{p}$ spaces .......................

Arne Stray, Interpolation by analytic functions

$\mathrm{Li} \mathrm{Pi} \mathrm{Su}$, Rings of analytic functions on any subset of the complex plane.

R. J. Tondra, A property of manifolds compactly equivalent to compact manifolds.... 